\title{
Analysis of Circuit Operation under ZVS and NON-ZVS Conditions in Phase-Shift Inverter for Induction Heating
}

\author{
Pichetjamroen Viriya Non-member (King Mongkut's Institute of Technology Ladkrabang) \\ Naras Yongyuth Non-member (King Mongkut's Institute of Technology Ladkrabang) \\ Ichiro Miki Member (Meiji University) \\ Kouki Matsuse Member (Meiji University)
}

Keywords: circuit operation, ZVS, NON-ZVS, phase-shift, induction heating, high-frequency

In the full-bridge phase-shift resonant inverter of Fig. 1 where MOSFET is used as a switching device, there is a small value of capacitance $\mathbf{C}_{\text {oss }}$ existing between drain-source of the MOSFET. This is not generally taken into consideration in terms of its effect on the circuit operation because the inverter is operated over resonant frequency and the device switches correctly at zero voltage switching (ZVS) and there is not any damage caused to the switching device under this operating frequency, but in case that the inverter frequency approaches resonant frequency in order to obtain maximum power or in case that phase-shift control is applied to the inverter in order to reduce the output power to the required level, the value of $\mathbf{C}_{\text {oss }}$ must be taken into consideration; otherwise the device may switches incorrectly at non-zero voltage switching (NON-ZVS) and can cause breakdown to the device.

So, the main target for this research work is to analyze the circuit operation of the full-bridge phase-shift resonant inverter with a load of induction heating, taking $\mathbf{C}_{\text {oss }}$ into consideration in order to obtain clearly all the voltage and current waveforms in the circuit. These calculated waveforms can be further used to determine the region of circuit operation which can be divided by a borderline into two regions of safety (ZVS) and unsafety (NON-ZVS). For the case of ZVS, the circuit operation over one cycle of output voltage can be divided into 10 modes (Modes (1) (2) (3) (4) (5) and (11) (21) (31) (4) (5)) as shown by output voltage and current waveforms in Fig. 2. Similarly, for the case of NON-ZVS, the circuit operation over one cycle can also be divided into another 10 modes (Modes (2) (3) (4) (5) (6) and (21) (31) (41) (51) (6)) as shown by output voltage and current waveforms in Fig. 3.

Without modes in ZVS and (1) (1) modes (6) (6) in NON-ZVS operations, the two cases of ZVS and NON-ZVS circuit operations become identical with exactly the same circuit operation of 8 modes (Modes (2) (3) (4) (5) and (21) (31) (4) (5)) as shown by output voltage and current waveforms in Fig. 4. This is referred to as critical ZVS operation in this paper and corresponds to the borderline mentioned above. There will be a certain borderline between ZVS and NONZVS circuit operation regions under a constant work-piece temperature. This paper also proposes a method to find out the borderline by calculating the critical value of some parameters where the following four parameters will be in our interest: (1) critical switching frequency $\left(\boldsymbol{f}_{s, c}\right),(2)$ critical load peak current $\left(\boldsymbol{I}_{p k, c}\right),(3)$ critical phase-lag $\left(\boldsymbol{\theta}_{1, c}\right)$ and (4) critical front-edge charging time $\left(\boldsymbol{T}_{C F, C}\right)$. Fig. 5 shows one kind of the variations of these four parameters at temperatures $100^{\circ} \mathrm{C}$ and $400^{\circ} \mathrm{C}$, where critical switching frequency, $\boldsymbol{f}_{s, c}$ vs. phase-shift, $\boldsymbol{\phi}$ is plotted in two curves of simulation and experimental results for verification and comparison purposes. From this figure, it is obvious that the borderline can clearly divide the circuit operation into two regions of ZVS and NON-ZVS and that under a constant temperature of work-piece at $100^{\circ} \mathrm{C}$ or $400^{\circ} \mathrm{C}$, there must be a slight increase of critical switching frequency with the increase of phase-shift in the range of $10^{\circ} \sim 80^{\circ}$; otherwise the circuit

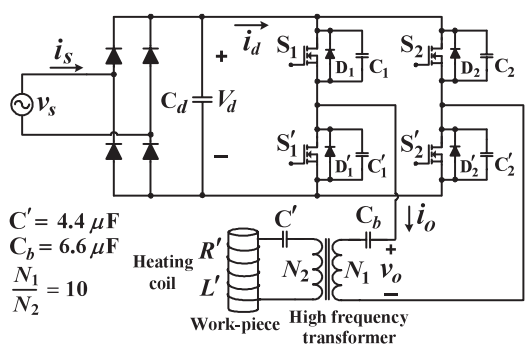

Fig. 1. Phase-shift inverter fed induction heating

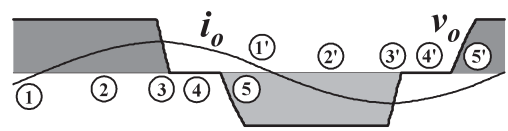

Fig. 2. Output voltage and current waveforms under ZVS

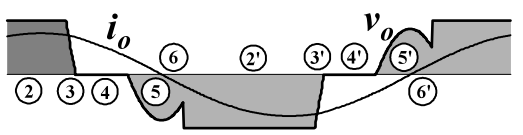

Fig. 3. Output voltage and current waveforms under NON-ZVS

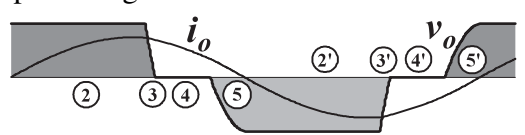

Fig. 4. Output voltage and current waveforms under Crit. ZVS

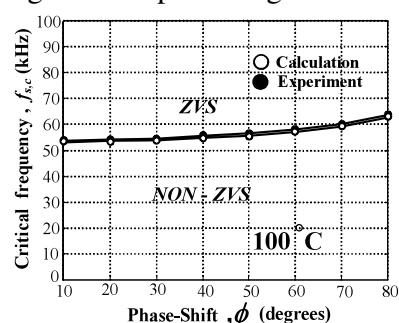

(a) work-piece at $100^{\circ} \mathrm{C}$

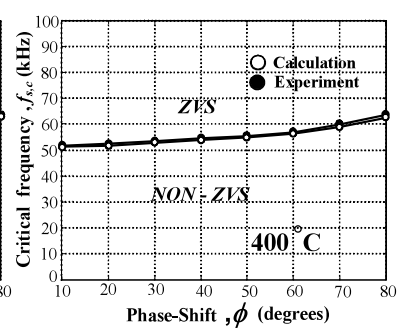

(b) work-piece at $400^{\circ} \mathrm{C}$
Fig. 5. Critical switching frequency $\boldsymbol{f}_{s, c}$ vs. Phase-Shift

$\phi$ at work-piece temperatures (a) $100^{\circ} \mathrm{C}$ and (b) $400^{\circ} \mathrm{C}$

operation will be driven into the region of NON-ZVS and consequently the breakdown will be caused to the device. In this paper, we also determine the effect of temperature of work-piece on the borderline by simulation and experiment at three constant values of temperature $\left(100^{\circ} \mathrm{C}, 250^{\circ} \mathrm{C}\right.$ and $\left.400^{\circ} \mathrm{C}\right)$ and it comes out that there is only a slight displacement effect on the borderline as shown in Figs. 5(a) and 5(b).

In conclusion, the circuit mode analysis proposed in this paper can be confirmed to be correct by MATLAB simulation with experimental verification. This can lead further to the calculation of borderlines of some parameters that can be used to divide the circuit operation into two regions of ZVS and NON-ZVS. It can also be shown from the analysis results that these borderlines can be hardly affected by the temperature change of work-piece in the range of $100^{\circ} \mathrm{C} \sim 400^{\circ} \mathrm{C}$. 


\title{
Analysis of Circuit Operation under ZVS and NON-ZVS Conditions in Phase-Shift Inverter for Induction Heating
}

\author{
Pichetjamroen Viriya* Non-member \\ Naras Yongyuth* Non-member \\ Ichiro Miki** \\ Member \\ Kouki Matsuse** Member
}

This paper presents a detailed analysis of circuit operation under ZVS and NON-ZVS conditions in a full-bridge high-frequency phase-shift control series resonant MOSFET inverter with the load of induction heating. Various modes of circuit operation both under ZVS and NON-ZVS conditions are first analyzed in details. The voltage and current equations of these circuits are then obtained and used for calculation of the waveforms by MATLAB program. The calculated results can lead to the consideration of various circuit parameters that determine ZVS or NON-ZVS operating conditions. The theoretical results are also verified by experimental ones, using a prototype test set rated at $3 \mathrm{~kW}$.

Keywords: circuit operation, ZVS, NON-ZVS, phase-shift, induction heating, high-frequency

\section{Introduction}

In the single-phase full-bridge inverter circuit using MOSFET power switching device with a load of induction heating, one important problem encountered in the circuit is when the inverter is operated with phase-shift control since the switching frequency $\boldsymbol{f}_{s}$ must be always slightly increased with the increase of phase-shift in order to maintain the inverter to operate under Zero Voltage Switching, ZVS condition ${ }^{(1)(2)}$ which is regarded as an important necessary operating condition. The main reason for this is generally understood that the output capacitor $\mathrm{C}_{\mathrm{oss}}$ in the switching power MOSFET ${ }^{(2)(3)}$ must be controlled to entirely discharge itself before the next coming turn-on ${ }^{(2)}$, but the detailed analysis to explain the internal operating mechanism of the circuit both theoretically and experimentally is still kept unreported. This is a very interesting problem and is taken as our research topic in this paper. In order to solve this problem, the single-phase fullbridge series resonant inverter with a load of induction heating has been developed in our laboratory as shown in Fig. 1, in which when the inverter is operated with powering mode of circuit operation as shown in Fig. 2, each pair of switches $S_{1}-S_{2}^{\prime}$ and $S_{2}-S_{1}^{\prime}$ normally turns on and off alternately in order to generate AC step-wave output voltage. In this case, if each power switching device is MOSFET as used in this paper, the output capacitors $C_{\text {oss }}$ which exist actually between drainsource of the device and is equal to $870 \times 2 \mathrm{pF}$ for a parallel connection of two pieces of IRFP460 must be also taken into consideration. For clarity of waveform investigation during

\footnotetext{
* Dept. of Electrical Engineering, Faculty of Engineering, King Mongkut's Institute of Technology Ladkrabang, 10520, Bangkok, Thailand, Tel. 662-7373000 EXT. 3516 Fax. 662-3264550

E-Mail : kpviriya@kmitl.ac.th and yongyuth_nar@yahoo.com

** School of Science and Technology, Meiji University

1-1-1, Higashimita, Tama-ku, Kawasaki-shi 214, Japan

Tel. 03(3296)4000, +81-44-934-7293, Fax. 03(3296)4339

E-Mail: matsuse@ics.meiji.ac.jp
}

charge transfer (Modes (3), (5) and (3), (5) in Fig. 2), $\mathrm{C}_{1}, \mathrm{C}_{1}^{\prime}$, $\mathrm{C}_{2}, \mathrm{C}_{2}^{\prime}$ each of which is equal in value, is made equal to $\mathrm{C}_{\mathrm{oss}}$ $+2200 \mathrm{pF}$ and is given as drain-source capacitance: $\mathrm{C}_{\mathrm{ds}}$. By principle, the capacitors $\mathrm{C}_{2}$ and $\mathrm{C}_{1}^{\prime}$ as shown in Fig. 2 will be fully charged by the supply voltage $V_{d}$ during the on-state of switch pair $S_{1}-S_{2}^{\prime}$ in the positive half-cycle of output voltage $v_{o}$. Alternately, in the next sequence of negative half-cycle where switch pair $S_{2}-S_{1}^{\prime}$ enters the on-state in turn as shown in Fig. 2, the fully charged capacitors $C_{2}$ and $C_{1}^{\prime}$ must completely discharge themselves before the next coming turn-on process.

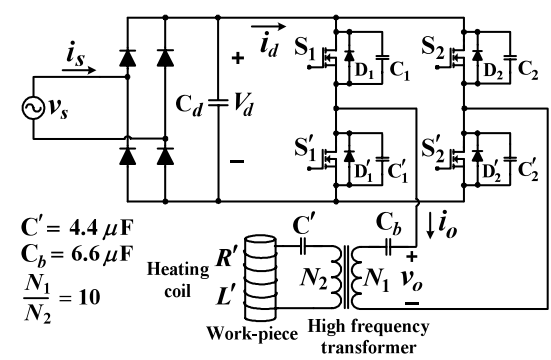

Fig. 1. Phase-shift inverter fed induction heating

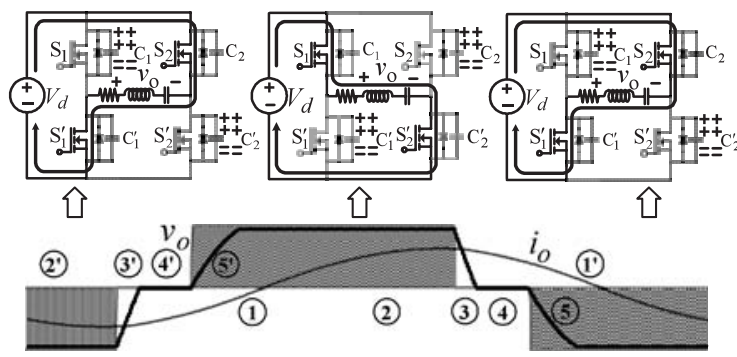

Fig. 2. The idea to point out a main point of problem: How to transfer charges up or down in each inverter branch circuit between each powering mode of output voltage $v_{o}$ 
Therefore, how can the charges in the capacitor pair $\mathrm{C}_{2}$ $\mathrm{C}_{1}^{\prime}$ transfer to the other remaining pair of capacitors $\mathrm{C}_{1}-\mathrm{C}_{2}^{\prime}$ or vice versa still remains as a main point of problem that waits for an analysis method to solve. One such method to solve this problem has been already presented clearly in this paper both theoretically and experimentally in the following sections.

\section{Analysis of Circuit Operation with Calculated and Experimental Waveforms}

2.1 Modes of Circuit Operation First, we show various modes of circuit operation of the main power circuit as in Figs. 3 which have totally 10 modes for two different operating conditions. One is for the case of Zero-Voltage

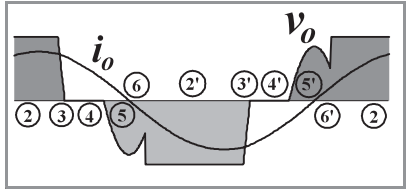

NON-ZVS

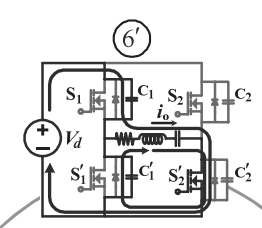

NON-ZVS
(1)
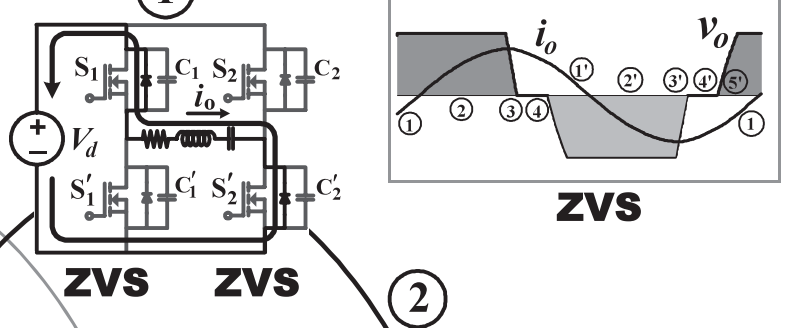

ZVS

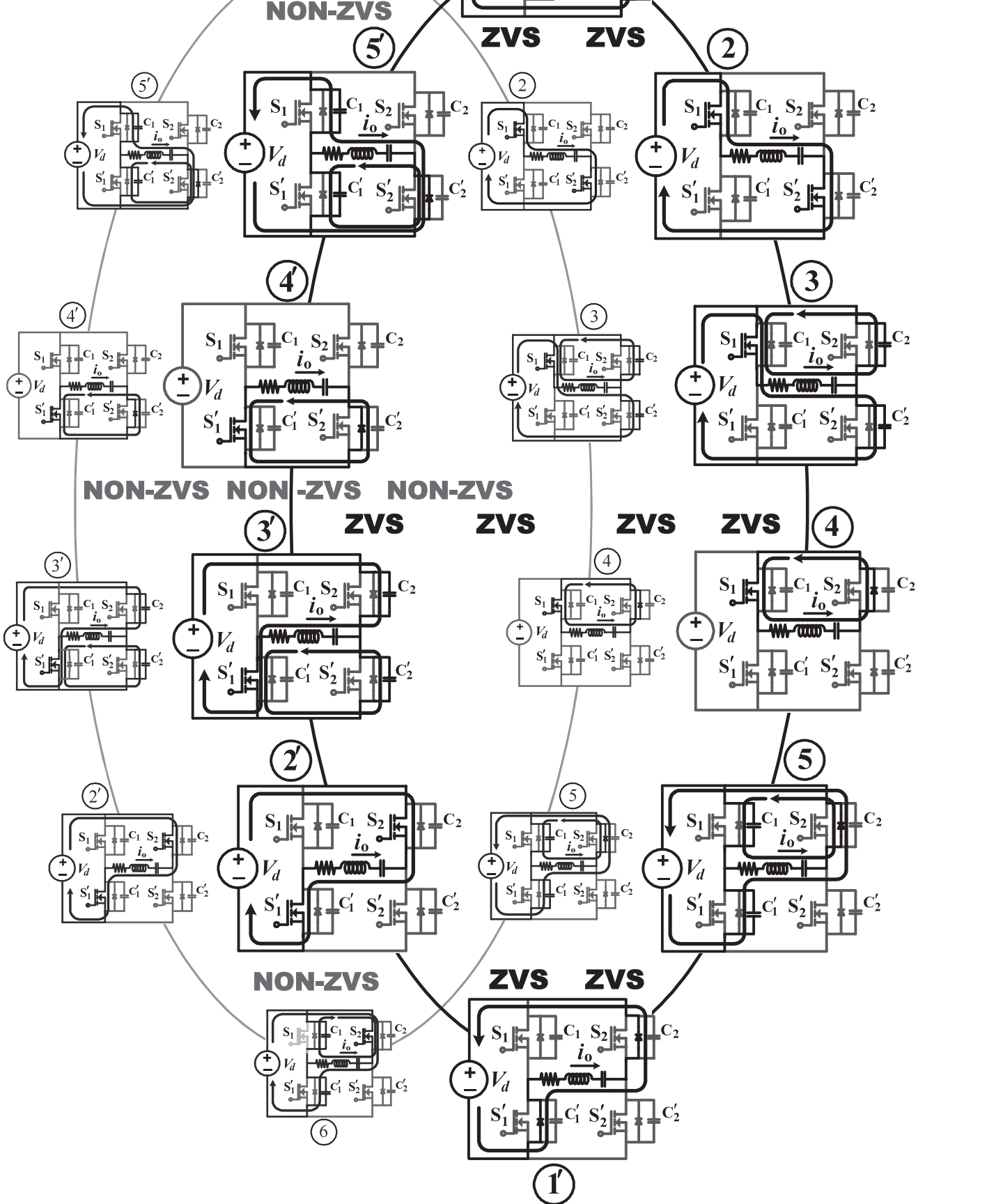

Fig. 3. Circuit operation modes under ZVS condition (Modes (1) (2) (3) (4) (5) (1) (2) (3) (4) and (5)) and under NON-ZVS condition (Modes (2) (3) (4) (5) (6) (2) (3) (4) (5) and (6)) 
Switching, ZVS (Modes (1) (2) (3) (4) (5) (1) (2) (3) (4) and (5)) and the other case is for the condition of Non-Zero-Voltage Switching, NON-ZVS (Modes (2) (3) (4) (5) (6) (2) (3) (4) (5) and (6)).

2.2 Voltage and Current Equations in Each Mode of Circuit Operation From these modes of circuit operation and by second order differential equations, various equations of output current $\boldsymbol{i}_{o}$ and output voltage $\boldsymbol{v}_{o}$ can also be obtained in two cases. One is for the operating condition of ZVS (Equations (1), (2), (3), (4), (5), (1'), (2'), (3'), (4') and $\left(5^{\prime}\right)$ ) and the other case is for the operating condition of NON-ZVS (Equations (2), (3), (4), (5), (6), (2'), (3'), (4'), $\left(5^{\prime}\right)$ and $\left.\left(6^{\prime}\right)\right)$.

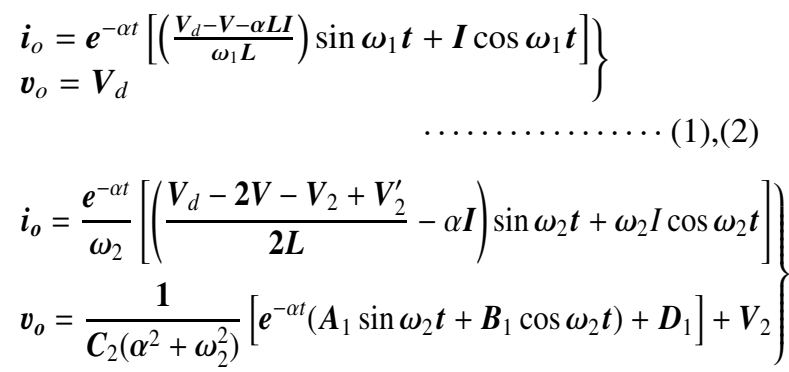

$$
\left.\begin{array}{l}
\boldsymbol{i}_{\boldsymbol{o}}=\boldsymbol{e}^{-\alpha t}\left[\left(\frac{-\boldsymbol{V}-\boldsymbol{\alpha} \boldsymbol{L I}}{\omega_{1} \boldsymbol{L}}\right) \sin \omega_{1} \boldsymbol{t}+\boldsymbol{I} \cos \omega_{1} \boldsymbol{t}\right] \\
\boldsymbol{v}_{\boldsymbol{o}}=\mathbf{0}
\end{array}\right\}
$$

$$
\left.\begin{array}{l}
i_{\boldsymbol{o}}=\frac{\boldsymbol{e}^{-\alpha t}}{\omega_{2}}\left[\left(\frac{-V_{d}-2 \boldsymbol{V}-V_{1}+V_{1}^{\prime}}{2 L}-\alpha \boldsymbol{I}\right) \sin \omega_{2} t+\omega_{2} I \cos \omega_{2} t\right] \\
\boldsymbol{v}_{\boldsymbol{o}}=\frac{1}{C_{1}\left(\alpha^{2}+\omega_{2}^{2}\right)}\left[e^{-\alpha t}\left(A_{2} \sin \omega_{2} t+\boldsymbol{B}_{2} \cos \omega_{2} t\right)+D_{2}\right]-V_{1}
\end{array}\right\}
$$

$$
\left.\begin{array}{l}
\boldsymbol{i}_{\boldsymbol{o}}=\boldsymbol{e}^{-\alpha t}\left[\left(\frac{-\boldsymbol{V}_{d}-\boldsymbol{V}-\boldsymbol{\alpha} \boldsymbol{L I}}{\omega_{1} \boldsymbol{L}}\right) \sin \omega_{1} \boldsymbol{t}+\boldsymbol{I} \cos \omega_{1} \boldsymbol{t}\right] \\
\boldsymbol{v}_{\boldsymbol{o}}=-\boldsymbol{V}_{\boldsymbol{d}}
\end{array}\right\}
$$

$$
\left.\begin{array}{l}
i_{\boldsymbol{o}}=\frac{\boldsymbol{e}^{-\alpha t}}{\omega_{2}}\left[\left(\frac{-V_{d}-2 V-V_{2}+V_{2}^{\prime}}{2 L}-\alpha \boldsymbol{I}\right) \sin \omega_{2} t+\omega_{2} I \cos \omega_{2} t\right] \\
\boldsymbol{v}_{\boldsymbol{o}}=\frac{1}{C_{2}^{\prime}\left(\alpha^{2}+\omega_{2}^{2}\right)}\left[\boldsymbol{e}^{-\alpha t}\left(A_{3} \sin \omega_{2} t+\boldsymbol{B}_{3} \cos \omega_{2} t\right)+D_{3}\right]-V_{2}^{\prime}
\end{array}\right\}
$$

$$
\begin{aligned}
& \left.\boldsymbol{i}_{\boldsymbol{o}}=\boldsymbol{e}^{-\alpha t}\left[\left(\frac{-\boldsymbol{V}-\boldsymbol{\alpha} \boldsymbol{L I}}{\omega_{1} \boldsymbol{L}}\right) \sin \omega_{1} t+\boldsymbol{I} \cos \omega_{1} t\right]\right\} \ldots \\
& \boldsymbol{v}_{\boldsymbol{o}}=\mathbf{0}
\end{aligned}
$$

$$
\left.\begin{array}{l}
i_{\boldsymbol{o}}=\frac{\boldsymbol{e}^{-\alpha t}}{\omega_{2}}\left[\left(\frac{V_{d}-2 \boldsymbol{V}-V_{1}+V_{1}^{\prime}}{2 L}-\alpha \boldsymbol{I}\right) \sin \omega_{2} t+\omega_{2} I \cos \omega_{2} t\right] \\
\boldsymbol{v}_{\boldsymbol{o}}=\frac{1}{C_{1}^{\prime}\left(\boldsymbol{\alpha}^{2}+\omega_{2}^{2}\right)}\left[\boldsymbol{e}^{-\alpha t}\left(\boldsymbol{A}_{4} \sin \omega_{2} t+\boldsymbol{B}_{4} \cos \omega_{2} t\right)+D_{4}\right]+\boldsymbol{V}_{1}^{\prime}
\end{array}\right\}
$$

Where;

$V_{1}$ : the initial value of voltage $\boldsymbol{V}_{\mathrm{C}_{1}}$
$\boldsymbol{V}_{1}^{\prime}$ : the initial value of voltage $\boldsymbol{V}_{\mathrm{C}_{1}^{\prime}}$

$\boldsymbol{V}_{2}$ : the initial value of voltage $\boldsymbol{V}_{\mathrm{C}_{2}}$

$\boldsymbol{V}_{2}^{\prime}$ : the initial value of voltage $\boldsymbol{V}_{\mathrm{C}_{2}^{\prime}}$

$\boldsymbol{I}$ : the initial value of load current $\boldsymbol{i}_{\boldsymbol{o}}$ in each mode of circuit operation

$\boldsymbol{V}$ : the initial value of load capacitor voltage in each mode of circuit operation

$$
\begin{aligned}
& \omega_{1}=\sqrt{\frac{1}{L C}-\left(\frac{R}{2 L}\right)^{2}} \\
& \omega_{2}=\sqrt{\left(\frac{1}{L C}+\frac{1}{2 L C_{d s}}\right)-\left(\frac{R}{2 L}\right)^{2}} \\
& \alpha=\frac{R}{2 L} \\
& A_{1}=\frac{\left[\begin{array}{l}
\boldsymbol{R} \boldsymbol{C}_{d s}\left(\boldsymbol{V}_{d}-\boldsymbol{V}_{2}-\boldsymbol{V}_{2}^{\prime}\right)\left(\boldsymbol{\alpha}^{2}+\omega_{2}^{2}\right)-\boldsymbol{L I}\left(\alpha^{2}+\omega_{2}^{2}\right)-\alpha\left(\boldsymbol{V}-\boldsymbol{V}_{2}\right) \\
-\alpha\left(\boldsymbol{C}_{d s} / \boldsymbol{C}\right)\left(\boldsymbol{V}_{d}-V_{2}-V_{2}^{\prime}\right)-\alpha \boldsymbol{C}_{d s} \boldsymbol{L}\left(\boldsymbol{V}_{d}-\boldsymbol{V}_{2}-\boldsymbol{V}_{2}^{\prime}\right)\left(\boldsymbol{\alpha}^{2}+\omega_{2}^{2}\right)
\end{array}\right]}{2 \omega_{2} L} \\
& B_{1}=\frac{\left(-C_{d s} / C\right)\left(V_{d}-V_{2}-V_{2}^{\prime}\right)-\left(V-V_{2}\right)+C_{d s} L\left(V_{d}-V_{2}-V_{2}^{\prime}\right)\left(\alpha^{2}+\omega_{2}^{2}\right)}{2 L} \\
& \boldsymbol{D}_{1}=\frac{\left(\boldsymbol{C}_{d s} / \boldsymbol{C}\right)\left(\boldsymbol{V}_{d}-\boldsymbol{V}_{2}-\boldsymbol{V}_{2}^{\prime}\right)+\left(\boldsymbol{V}-\boldsymbol{V}_{2}\right)}{\mathbf{2} \boldsymbol{L}}
\end{aligned}
$$$$
\left[\boldsymbol{R C}_{d s}\left(-\boldsymbol{V}_{d}+\boldsymbol{V}_{1}+\boldsymbol{V}_{1}^{\prime}\right)\left(\boldsymbol{\alpha}^{2}+\omega_{2}^{2}\right)-\boldsymbol{L I}\left(\boldsymbol{\alpha}^{2}+\omega_{2}^{2}\right)-\boldsymbol{\alpha}\left(\boldsymbol{V}+\boldsymbol{V}_{1}\right)\right.
$$$$
A_{2}=\frac{\left.-\alpha\left(C_{d s} / C\right)\left(-V_{d}+V_{1}+V_{1}^{\prime}\right)-\alpha C_{d s} L\left(-V_{d}+V_{1}+V_{1}^{\prime}\right)\left(\alpha^{2}+\omega_{2}^{2}\right)\right]}{2 \omega_{2} L}
$$$$
B_{2}=\frac{\left(-C_{d s} / C\right)\left(-V_{d}+V_{1}+V_{1}^{\prime}\right)-\left(V+V_{1}\right)+C_{d s} L\left(-V_{d}+V_{1}+V_{1}^{\prime}\right)\left(\alpha^{2}+\omega_{2}^{2}\right)}{2 L}
$$$$
\boldsymbol{D}_{2}=\frac{\left(\boldsymbol{C}_{d s} / \boldsymbol{C}\right)\left(-\boldsymbol{V}_{d}+\boldsymbol{V}_{1}+\boldsymbol{V}_{1}^{\prime}\right)+\left(\boldsymbol{V}+\boldsymbol{V}_{1}\right)}{\mathbf{2 L}}
$$$$
R C_{d s}\left(-V_{d}+V_{2}+V_{2}^{\prime}\right)\left(\alpha^{2}+\omega_{2}^{2}\right)-L I\left(\alpha^{2}+\omega_{2}^{2}\right)-\alpha\left(V+V_{2}^{\prime}\right)
$$$$
A_{3}=\frac{\left[-\alpha\left(C_{d s} / C\right)\left(-V_{d}+V_{2}+V_{2}^{\prime}\right)-\alpha C_{d s} L\left(-V_{d}+V_{2}+V_{2}^{\prime}\right)\left(\alpha^{2}+\omega_{2}^{2}\right)\right.}{2 \omega_{2} L}
$$$$
B_{3}=\frac{\left(-C_{d s} / C\right)\left(-V_{d}+V_{2}+V_{2}^{\prime}\right)-\left(V+V_{2}^{\prime}\right)+C_{d s} L\left(-V_{d}+V_{2}+V_{2}^{\prime}\right)\left(\alpha^{2}+\omega_{2}^{2}\right)}{2 L}
$$$$
\boldsymbol{D}_{3}=\frac{\left(\boldsymbol{C}_{d s} / \boldsymbol{C}\right)\left(-\boldsymbol{V}_{d}+\boldsymbol{V}_{2}+\boldsymbol{V}_{2}^{\prime}\right)+\left(\boldsymbol{V}+\boldsymbol{V}_{2}^{\prime}\right)}{\mathbf{2} \boldsymbol{L}}
$$

$\left[\boldsymbol{R} \boldsymbol{C}_{d s}\left(\boldsymbol{V}_{d}-\boldsymbol{V}_{1}-\boldsymbol{V}_{1}^{\prime}\right)\left(\boldsymbol{\alpha}^{2}+\omega_{2}^{2}\right)-\boldsymbol{L I}\left(\boldsymbol{\alpha}^{2}+\omega_{2}^{2}\right)-\alpha\left(\boldsymbol{V}-\boldsymbol{V}_{1}^{\prime}\right)\right.$ $A_{4}=\frac{\left.-\alpha\left(C_{d s} / C\right)\left(V_{d}-V_{1}-V_{1}^{\prime}\right)-\alpha C_{d s} L\left(V_{d}-V_{1}-V_{1}^{\prime}\right)\left(\alpha^{2}+\omega_{2}^{2}\right)\right]}{2 \omega_{2} L}$

$B_{4}=\frac{\left(-C_{d s} / C\right)\left(V_{d}-V_{1}-V_{1}^{\prime}\right)-\left(V-V_{1}^{\prime}\right)+C_{d s} L\left(V_{d}-V_{1}-V_{1}^{\prime}\right)\left(\alpha^{2}+\omega_{2}^{2}\right)}{2 L}$

$\boldsymbol{D}_{4}=\frac{\left(\boldsymbol{C}_{d s} / \boldsymbol{C}\right)\left(\boldsymbol{V}_{d}-\boldsymbol{V}_{1}-\boldsymbol{V}_{1}^{\prime}\right)+\left(\boldsymbol{V}-\boldsymbol{V}_{1}^{\prime}\right)}{\mathbf{2 L}}$

2.3 Calculated and Experimental Waveforms Using the above equations and by MATLAB program, all voltages and currents in various parts of the circuit can be solved and presented in various waveforms as shown in Figs. 4 and 5(a) for the case of ZVS operating condition with the theoretical output voltage and current waveforms of Fig. 5(a) verified by experimental results of Fig. 5(b). In the same way, the similar waveforms as shown in Figs. 6 and 7(a) for the case of NON-ZVS operating condition can also be obtained with the theoretical output voltage and current waveforms of Fig. 7(a) verified by experimental results of Fig. 7(b). Again, by using the same method, the theoretical and experimental output voltage and current waveforms for the case of small peak load current $\boldsymbol{I}_{p k}$ with a large increase of phase-shift $\boldsymbol{\phi}$ can also be obtained as shown in Fig. 8(a) and (b) for verification purpose which is also the case for NON-ZVS circuit 


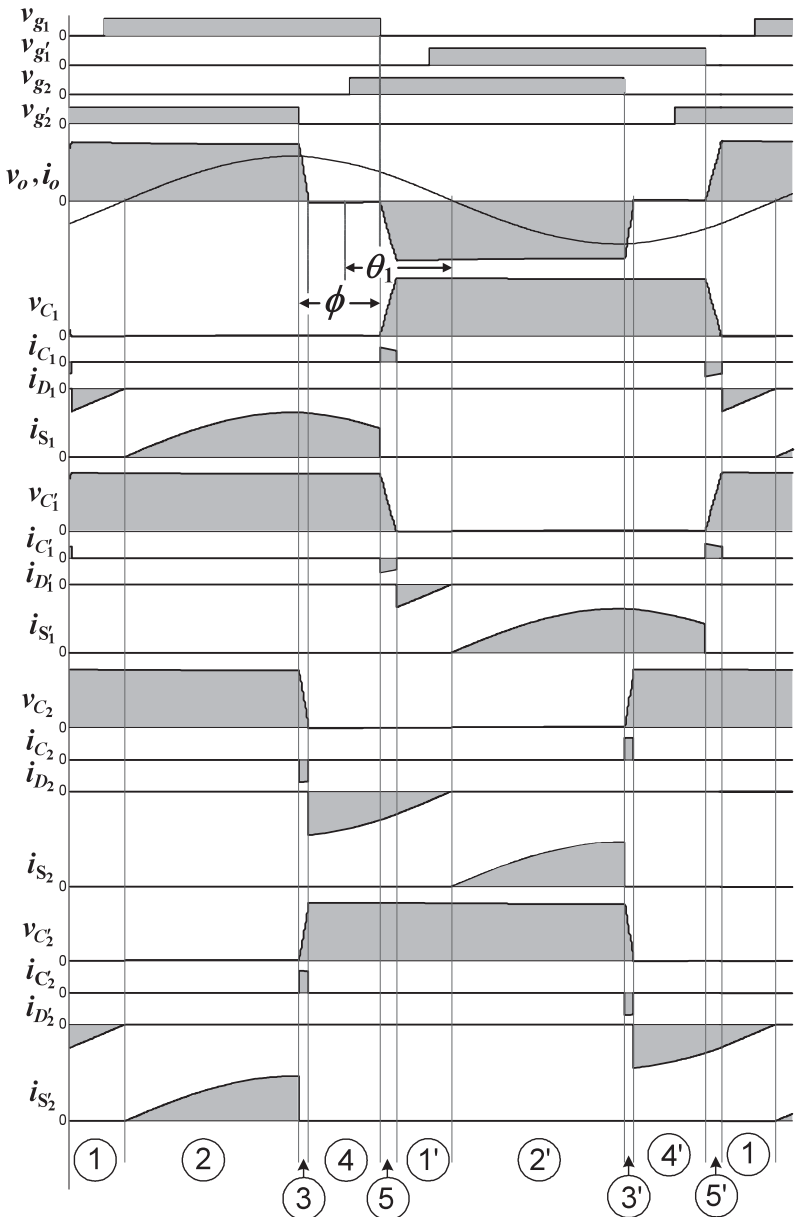

Fig. 4. Calculated voltage and current waveforms under ZVS operating condition

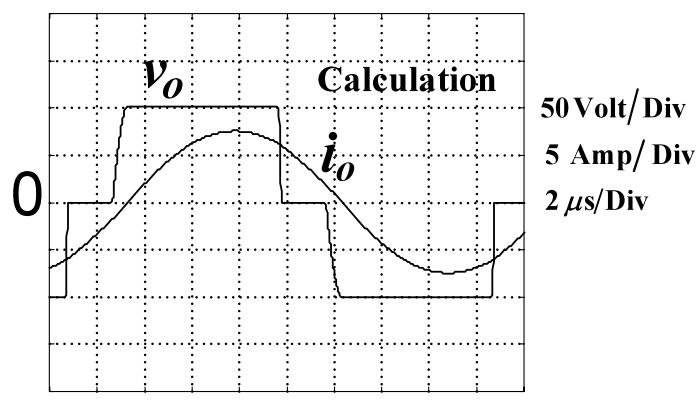

(a) Calculation

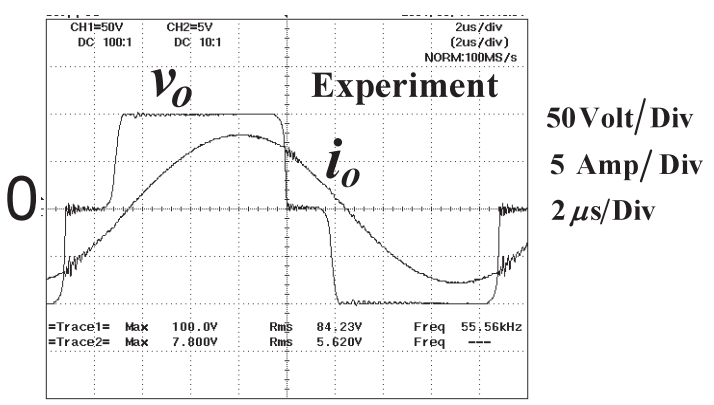

(b) Experiment

Fig. 5. Comparison of calculated and experimental output voltage and current waveforms under ZVS operating condition at phase-shift $\phi=40^{\circ}$

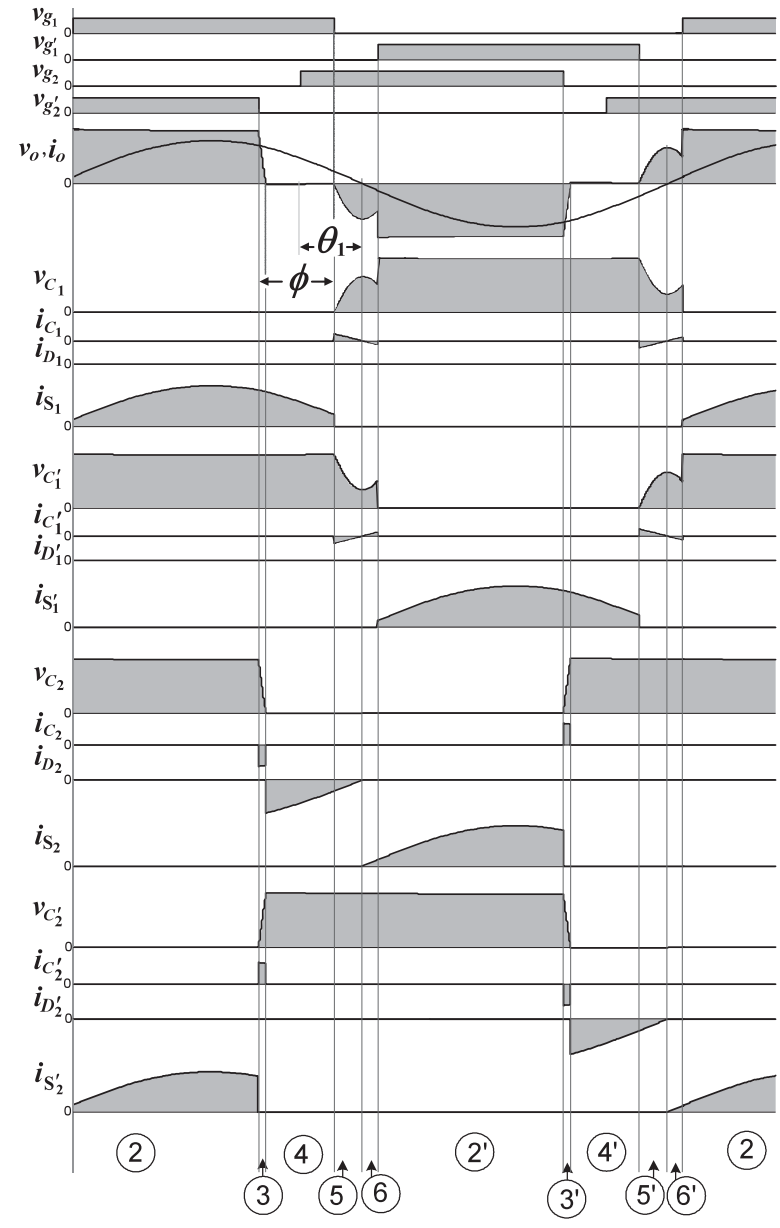

Fig. 6. Calculated voltage and current waveforms under NON-ZVS operating condition

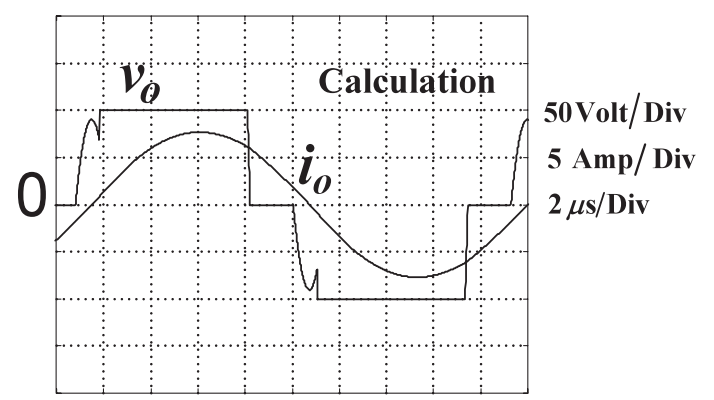

(a) Calculation

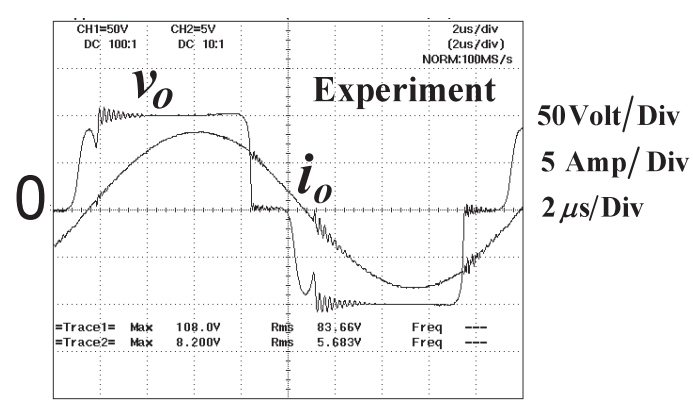

(b) Experiment

Fig. 7. Comparison of calculated and experimental output voltage and current waveforms under NON-ZVS operating condition at phase-shift $\phi=40^{\circ}$ 


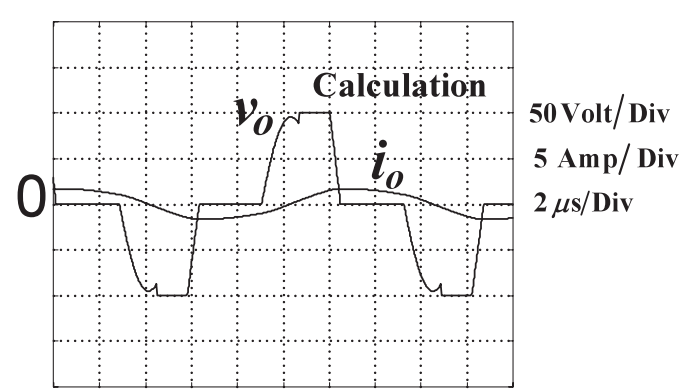

(a) Calculation

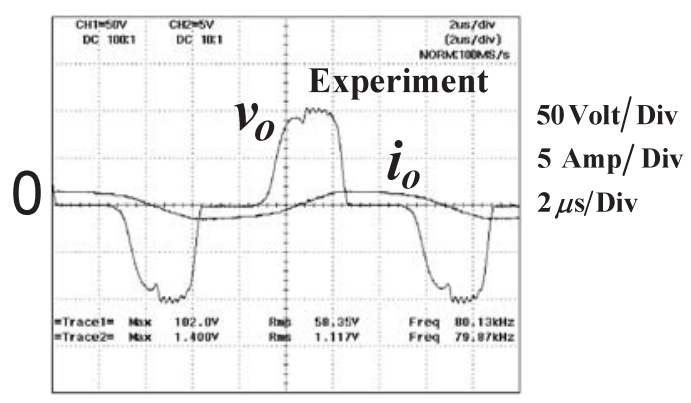

(b) Experiment

Fig. 8. Comparison of calculated and experimental output voltage and current waveforms under NON-ZVS operating condition due to large phase-shift $\left(\phi=90^{\circ}\right)$ and insufficient load current $\boldsymbol{I}_{p k}$

operation.

\section{Detailed Considerations of ZVS, NON-ZVS and Critical ZVS}

From the good understanding of modes of circuit operation described in Section 2, the next step concerning the details of ZVS, NON-ZVS and critical ZVS operating conditions at the front and tailing edges of output step voltage can also be understood as shown in the following details.

For the front edge of positive half-cycle of voltage $v_{o}$ as shown in Fig. 9, the charges in branch 1 are transferred downward from capacitor $C_{1}$ to $C_{1}^{\prime}$ with three possible operating conditions: (1) ZVS, (2) Critical ZVS and (3) NON-ZVS. For the front edge of negative half-cycle of voltage $v_{o}$, the charge transfer situation in the same branch is the same but only the direction is reversed upward from $\mathrm{C}_{1}^{\prime}$ to $\mathrm{C}_{1}$.

For the tailing edge of positive half-cycle of voltage $v_{o}$, the charges in branch 2 are transferred downward from capacitor $\mathrm{C}_{2}$ to $\mathrm{C}_{2}^{\prime}$ with only one possible operating condition: (1) $\mathrm{ZVS}$. For the tailing edge of negative half-cycle of voltage $v_{o}$ the charges transfer situation in the same branch is the same but only the direction is reversed upward from $\mathrm{C}_{2}^{\prime}$ to $\mathrm{C}_{2}$. The more details are also described in the following four sections.

3.1 ZVS Operation at the Front Edge of Voltage $v_{o}$ Fig. 10 shows the complete charge-discharge or the successful transfer of charge from capacitors $C_{1}^{\prime}$ to $C_{1}$, which occurs in the first branch of the inverter under ZVS operating condition. This transfer of charge occurs at the front edge of the negative half-cycle of output voltage $v_{o}$ and corresponds to Mode 5 of the circuit operation of Fig. 3. This implies that switch $S_{1}^{\prime}$ when operated in powering mode can turn on safely with the voltage $v_{\mathrm{C}_{1}^{\prime}}$ across it equal to zero (ZVS). Fig. 10 also shows the successful transfer of charge from $C_{1}$ to $C_{1}^{\prime}$ for the

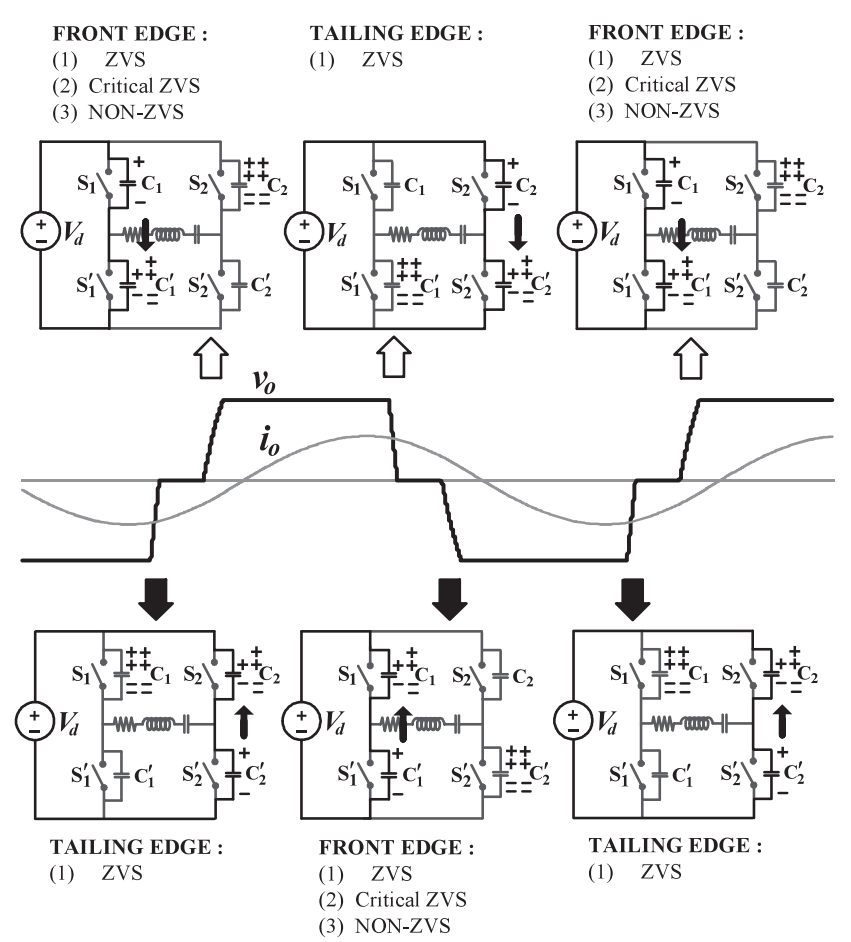

Fig. 9. The transfer of charges between each pair of capacitors in branches 1 and 2 of the inverter over 1-cycle of output voltage $v_{o}$

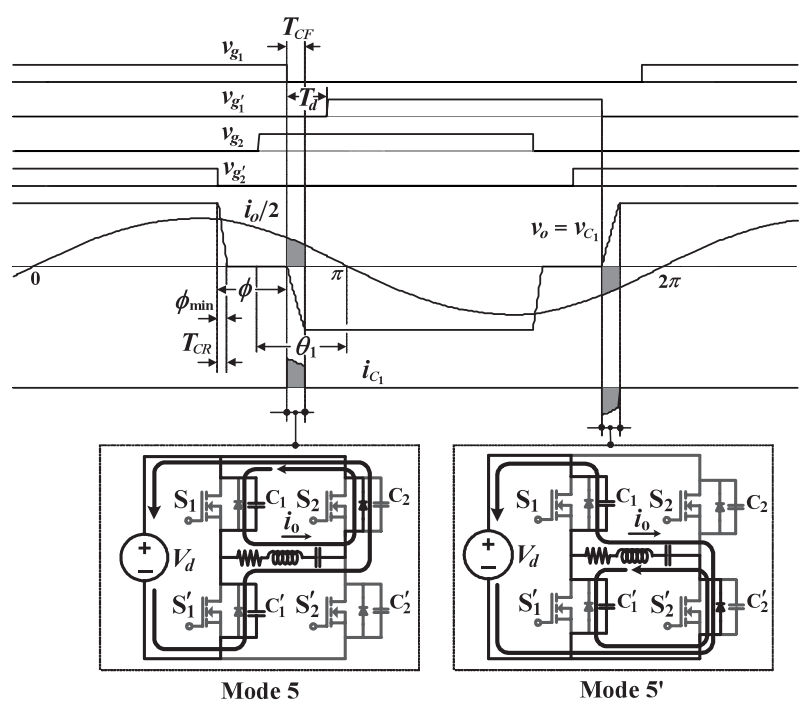

Fig. 10. Circuit operations of Modes 5 and $5^{\prime}$ from Fig. 3 showing the successful transfer of charge: Mode 5 from $\mathrm{C}_{1}^{\prime}$ to $\mathrm{C}_{1}$ for negative front edge of $v_{o}$ and Mode $5^{\prime}$ from $\mathrm{C}_{1}$ to $\mathrm{C}_{1}^{\prime}$ for positive front edge of $v_{o}$

next ZVS turn-on of switch $\mathrm{S}_{1}$. This transfer of charge occurs at the front edge of the positive half-cycle of output voltage $v_{o}$ and corresponds to Mode $5^{\prime}$ of the circuit operation of Fig. 3. Similarly, this implies that switch $S_{1}$ when operated in powering mode can turn on safely with the voltage $v_{\mathrm{C}_{1}}$ across it equal to zero (ZVS).

3.2 NON-ZVS Operation at the Front Edge of Voltage $\boldsymbol{v}_{\boldsymbol{o}} \quad$ Fig. 11 shows the incomplete charge-discharge or the unsuccessful transfer of charge from capacitors $C_{1}^{\prime}$ to $\mathrm{C}_{1}$, which occurs in the first branch of the inverter under 


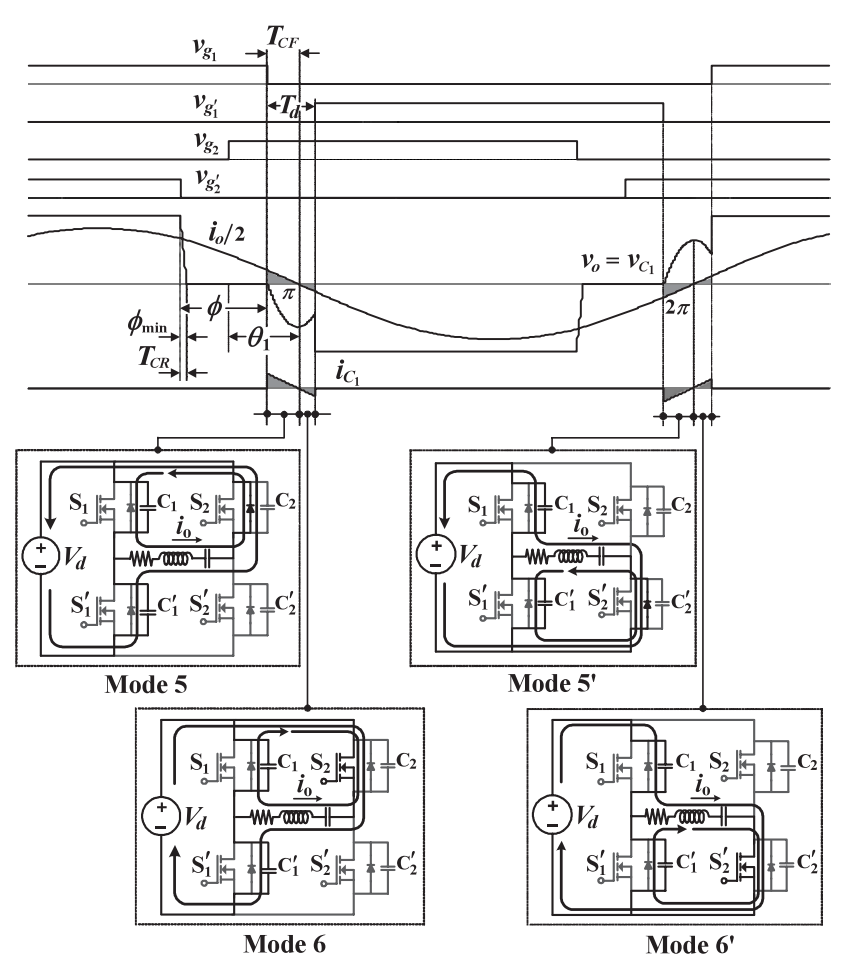

Fig. 11. Circuit operations of Modes $(5,6)$ and $\left(5^{\prime}, 6^{\prime}\right)$ Fig. 3 showing the unsuccessful transfer of charge: Mode 5 from $C_{1}^{\prime}$ to $C_{1}$ and Mode 6 back from $C_{1}$ to $C_{1}^{\prime}$ for negative front edge of $v_{o}$, Mode $5^{\prime}$ from $\mathrm{C}_{1}$ to $\mathrm{C}_{1}^{\prime}$ and Mode $6^{\prime}$ back from $\mathrm{C}_{1}^{\prime}$ to $\mathrm{C}_{1}$ for positive front edge of $v_{o}$

NON-ZVS operating condition which results in NON-ZVS operating condition of switch $S_{1}^{\prime}$ in the next turn-on sequence. This transfer of charge occurs at the front edge of the negative half-cycle of output voltage $v_{o}$ and corresponds to Modes 5 and 6 of the circuit operation of Fig. 3. This implies that switch $\mathrm{S}_{1}^{\prime}$ can not turn on safely with the voltage $v_{\mathrm{C}_{1}^{\prime}}$ across it not equal to zero (NON-ZVS). Fig. 11 also shows the unsuccessful transfer of charge from $\mathrm{C}_{1}$ to $\mathrm{C}_{1}^{\prime}$, which results in NON-ZVS operating condition of switch $S_{1}$ in the next turn-on sequence. This transfer of charge occurs at the front edge of the positive half-cycle of output voltage $v_{o}$ and corresponds to Modes $5^{\prime}$ and $6^{\prime}$ of the circuit operation of Fig. 3. Similarly, this implies that switch $\mathrm{S}_{1}$ can not turn on safely with the voltage $v_{\mathrm{C}_{1}}$ across it not equal to zero (NON-ZVS).

3.3 ZVS Operation at the Tailing Edge of Voltage $v_{o}$ Fig. 12 shows the complete charge-discharge or the successful transfer of charge from capacitors $C_{2}$ to $C_{2}^{\prime}$ in the second branch of the inverter under ZVS operating condition. This transfer of charge occurs at the tailing edge of the positive half-cycle of output voltage $v_{o}$ and corresponds to Mode 3 of the circuit operation of Fig. 3. Fig. 12 also shows the successful transfer of charge from $\mathrm{C}_{2}^{\prime}$ to $\mathrm{C}_{2}$ for the next ZVS turn-on of switch $\mathrm{S}_{2}^{\prime}$. This transfer of charge occurs at the tailing edge of the negative half-cycle of output voltage $v_{o}$ and corresponds to Mode $3^{\prime}$ of the circuit operation of Fig. 3. The circuit operation under NON-ZVS condition does not exist in this case because the charge-discharge of the second branch capacitors occurs around the peak position of sinusoidal half load current $i_{o} / 2$, which has higher charge-discharge current value when compared to that of lower charge-discharge

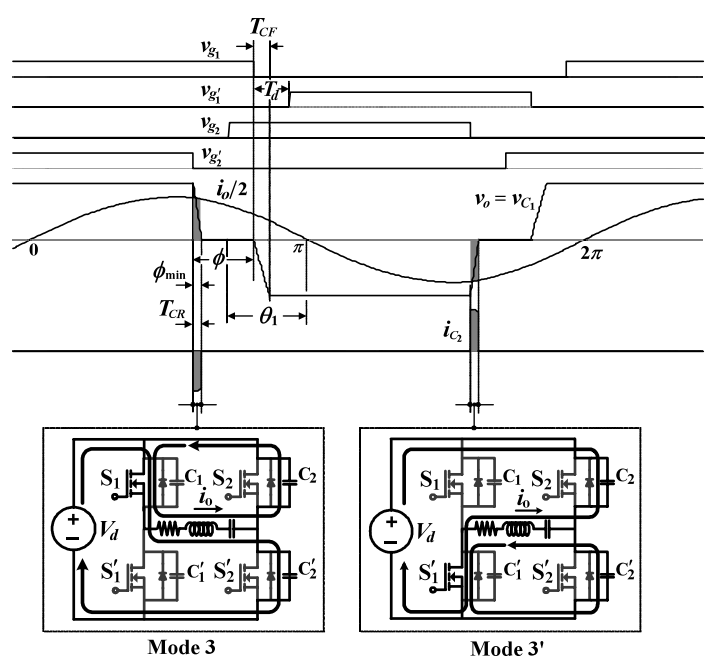

Fig. 12. Circuit operations of Modes 3 and $3^{\prime}$ from Fig. 3 showing the successful transfer of charge: Mode 3 from $\mathrm{C}_{2}$ to $\mathrm{C}_{2}^{\prime}$ for positive tailing edge of $v_{o}$ and Mode $3^{\prime}$ from $\mathrm{C}_{2}^{\prime}$ to $\mathrm{C}_{2}$ for negative tailing edge of $v_{o}$

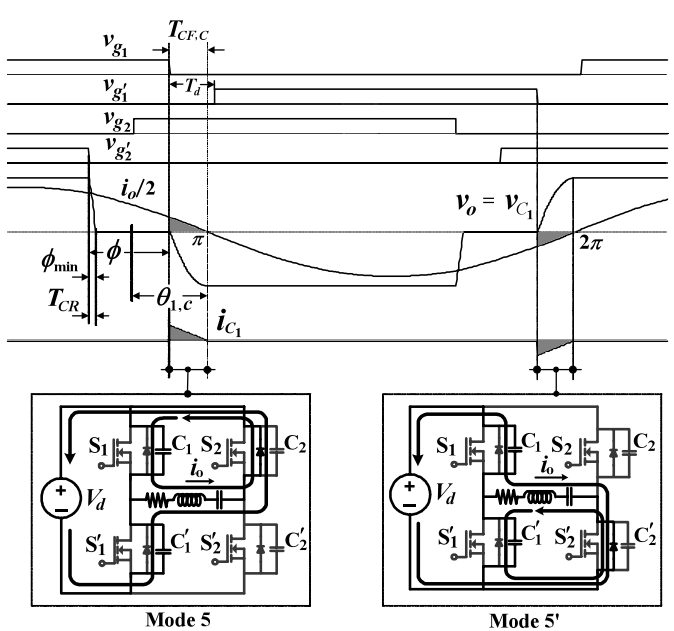

Fig. 13. Circuit operations of Modes 5 and $5^{\prime}$ from Fig. 3 showing the successful transfer of charge: Mode 5 from $\mathrm{C}_{1}^{\prime}$ to $\mathrm{C}_{1}$ for negative front edge of $v_{o}$ and Mode $5^{\prime}$ from $C_{1}$ to $C_{1}^{\prime}$ for positive front edge of $v_{o}$

current value around the zero-crossing position for the case of positive and negative front edge.

3.4 Critical ZVS Operation at the Front Edge of Voltage $v_{o} \quad$ Fig. 13 shows the charge-discharge of capacitor $\mathrm{C}_{1}$ and $\mathrm{C}_{1}^{\prime}$ in the first branch of the inverter under critical ZVS operating condition. The circuit operation in this case is the same as in case of ZVS in Section 3.1 except that the transfer of charge in this case is made completely at exactly the ends of positive and negative half-cycles of sinusoidal half load current $i_{o} / 2$.

\section{Calculated and Measured Characteristics of the Four Circuit Parameters vs. Phase-Shift under Critical ZVS Operating Condition}

As described in the previous section, the circuit operation of inverter with MOSFET drain-source capacitance: $\mathrm{C}_{\mathrm{ds}}$ can be divided into three different operating conditions; that is, ZVS, critical ZVS and NON-ZVS. In fact, critical ZVS is the borderline that is located between ZVS and NON-ZVS. 
So, the operating areas of ZVS and NON-ZVS during change of phase-shift can be determined by calculation of the four critical values of switching frequency $\boldsymbol{f}_{s, c}$, load peak current $\boldsymbol{I}_{p k, c}$, fundamental phase-lag $\boldsymbol{\theta}_{1, c}$ and front-edge charging time $\boldsymbol{T}_{C F, C}$, using the critical output voltage and current waveforms of Fig. 13; where the definitions of these critical parameters are as expressed by waveforms in Fig. 14.

From the waveforms of Fig. 13, the critical charging time $\boldsymbol{T}_{C F, C}$ for $\mathrm{C}_{1}$ or $\mathrm{C}_{1}^{\prime}$ can be obtained using Equation (7).

$\boldsymbol{T}_{C F, C}=\frac{\boldsymbol{\pi}-\left[\boldsymbol{\pi}-\left(\boldsymbol{\theta}_{1, c}-\frac{\boldsymbol{\phi}-\boldsymbol{\phi}_{\min }}{\mathbf{2}}\right)\right]}{\mathbf{2} \boldsymbol{\pi} \boldsymbol{f}_{s, c}}=\frac{\boldsymbol{\theta}_{1, c}-\frac{\boldsymbol{\phi}-\boldsymbol{\phi}_{\min }}{\mathbf{2}}}{\mathbf{2} \boldsymbol{\pi} \boldsymbol{f}_{s, c}} \cdots \cdots$

$\boldsymbol{R}=\left(\boldsymbol{V}_{o 1} / \boldsymbol{I}_{o 1}\right) \cos \boldsymbol{\theta}_{1, c} \ldots \ldots \ldots \ldots \ldots \ldots \ldots \ldots \ldots \ldots \ldots \ldots$

$\boldsymbol{L}=\left(\mathbf{1} / \mathbf{2} \boldsymbol{\pi} \boldsymbol{f}_{s, c}\right)\left[\left(\boldsymbol{V}_{o 1} / \boldsymbol{I}_{o 1}\right) \sin \boldsymbol{\theta}_{1, c}+\mathbf{1} /\left(\mathbf{2} \boldsymbol{\pi} \boldsymbol{f}_{s, c} \boldsymbol{C}\right)\right] \ldots \cdots$

All the parameters in Equation (7) can be determined by calculation using all the equations in Section 2.2 and when plotted with respect to change of phase-shift $\phi$ by MATLAB program, the characteristic curves of the four critical parameters: critical switching frequency $\boldsymbol{f}_{s, c}$, critical load peak current $\boldsymbol{I}_{p k, c}$, critical phase-lag $\boldsymbol{\theta}_{1, c}$, critical charging time $\boldsymbol{T}_{C F, C}$ under critical ZVS operating condition can be obtained as shown in Figs. 16, 17, 18 and 19, where the experimental results are also plotted in the same figures for comparison and the two results appear to be close to each other. Figs. 16, 17, 18 and 19 (left) show the relationship of these four critical parameters at heating work-piece temperature of $100^{\circ} \mathrm{C}$. It is obvious that when phase-shift $\phi$ is increased, the critical switching frequency $\boldsymbol{f}_{s, c}$ must be slightly increased in order to maintain the circuit to operate under critical ZVS operating condition. This results in a decrease of critical load peak

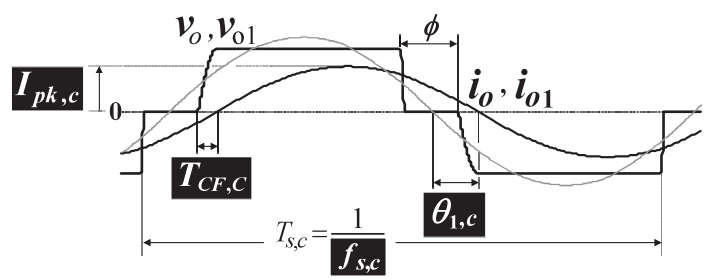

Fig. 14. The definitions of $\boldsymbol{f}_{s, c}, \boldsymbol{I}_{p k, c}, \boldsymbol{\theta}_{1, c}$ and $T_{C F, C}$

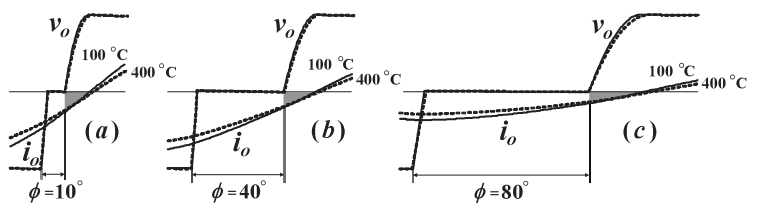

Fig. 15. $\boldsymbol{v}_{o}, \boldsymbol{i}_{o}$ at work-piece temperatures $100^{\circ} \mathrm{C}$ and $400^{\circ} \mathrm{C}$ : (a) $\phi=10^{\circ}$ (b) $\phi=40^{\circ}$ (c) $\phi=80^{\circ}$
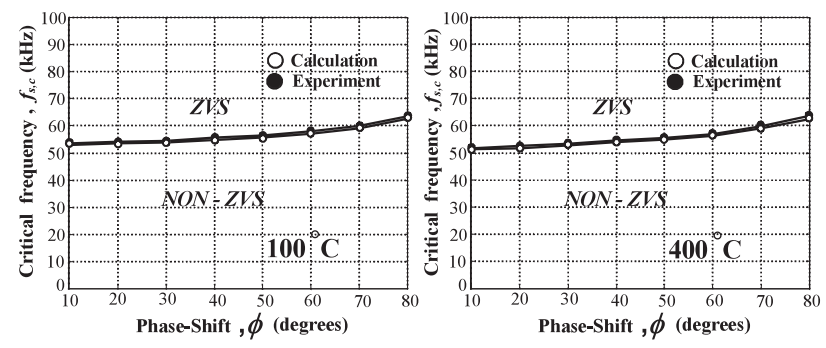

Fig. 16. Critical switching frequency $\boldsymbol{f}_{s, c}$ vs. Phase-Shift $\boldsymbol{\phi}$ current $\boldsymbol{I}_{p k, c}$ and increases of critical fundamental phase-lag $\boldsymbol{\theta}_{1, c}$ and critical charging time $\boldsymbol{T}_{C F, C}$. In the same figures, it is also understood that if any of these four critical parameters is changed away from its critical operating value, the inverter circuit will be driven into any of ZVS or NONZVS operating conditions as shown by the regions of ZVS and NON-ZVS in the figures. One more family of characteristic curves (right) is also obtained at different workpiece temperatures of $400^{\circ} \mathrm{C}$. It can be understood that increase of work-piece temperature from $100^{\circ} \mathrm{C} \sim 400^{\circ} \mathrm{C}$ results in gradual decreases of critical switching frequency $\boldsymbol{f}_{s, c}$ and critical load peak current $\boldsymbol{I}_{p k, c}$, but gradual increases of critical fundamental phase-lag $\boldsymbol{\theta}_{1, c}$ and critical charging time $\boldsymbol{T}_{C F, C}$. This is because the load equivalent resistance $\mathrm{R}$ and inductance $\mathrm{L}$ considered from the primary side of the output transformer change gradually in the temperature range from $100^{\circ} \mathrm{C} \sim 400^{\circ} \mathrm{C}$. The equivalent resistance $\mathrm{R}$ and inductance $\mathrm{L}$ at any work-piece temperature $\mathrm{T}$ and phase-shift $\phi$ can be calculated from the parameters $\boldsymbol{V}_{o 1}, \boldsymbol{I}_{o 1}, \boldsymbol{\theta}_{1, c}$ and $\boldsymbol{f}_{s, c}$, using Equations (8), (9), with these parameters defined as shown by waveforms in Fig. 14, and they can be determined from the experimental output waveforms $v_{o}, \boldsymbol{i}_{o}$ with their fundamental values $\boldsymbol{V}_{o 1} \boldsymbol{I}_{o 1}, \boldsymbol{\theta}_{1, c}$ obtained from Fourier analysis. By this method, the calculated values of equivalent $\mathrm{R}$ and $\mathrm{L}$ at workpiece temperatures $100^{\circ} \mathrm{C}, 400^{\circ} \mathrm{C}$ and phase-shifts $10^{\circ}, 40^{\circ}$, $80^{\circ}$ can be obtained as shown in Table 1 (uper part). Substituting these calculated values into Equations (1) (6) and
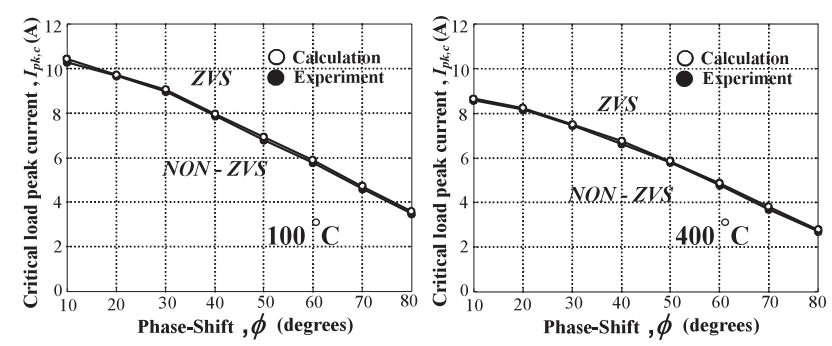

Fig. 17. Critical load peak current, $\boldsymbol{I}_{p k, c}$ vs. Phase-Shift $\boldsymbol{\phi}$
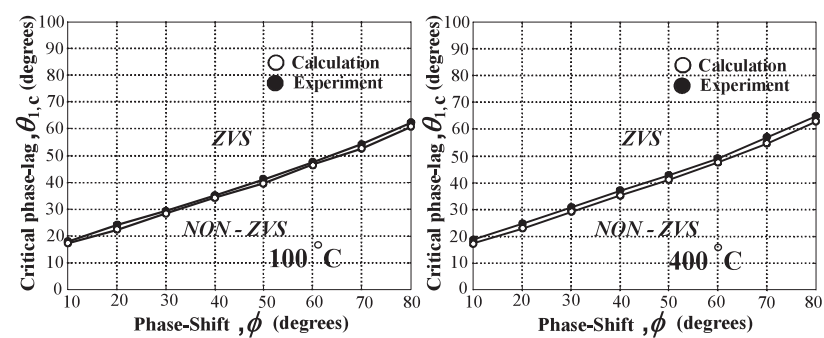

Fig. 18. Critical Phase-Lag, $\boldsymbol{\theta}_{1, C}$ vs. Phase-Shift $\boldsymbol{\phi}$
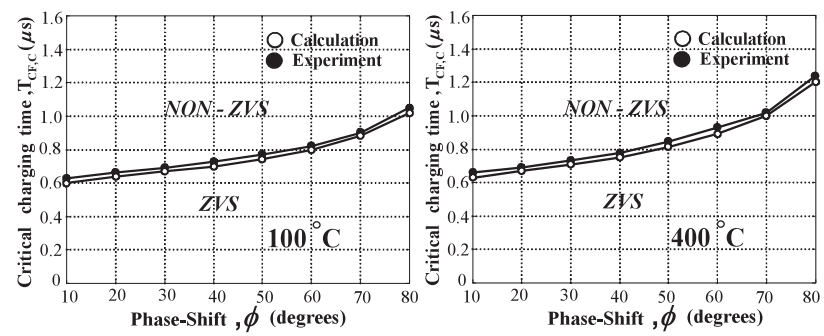

Fig. 19. Critical charging time, $\boldsymbol{T}_{C F, C}$ vs. Phase-Shift $\boldsymbol{\phi}$ 
Table 1. The calculated critical values of $\mathrm{R}, \mathrm{L}$ and $\boldsymbol{f}_{s, c}, \boldsymbol{I}_{p k, c}, \boldsymbol{\theta}_{1, c}, \boldsymbol{T}_{C F, C}$ at work-piece temperatures $100^{\circ} \mathrm{C}$, $400^{\circ} \mathrm{C}$, phase-shifts $\boldsymbol{\phi}=10^{\circ}, 40^{\circ}, 80^{\circ}$ and $\boldsymbol{V}_{d}=100 \mathrm{~V}$

\begin{tabular}{|l|c|c|c||c|c|c|}
\hline $\boldsymbol{T}\left({ }^{\circ} \mathbf{C}\right)$ & \multicolumn{3}{|c||}{} & $\mathbf{1 0 0}$ & \multicolumn{3}{|c|}{} & $\mathbf{4 0 0}$ & \\
\hline$\phi\left({ }^{\circ}\right)$ & $\mathbf{1 0}$ & $\mathbf{4 0}$ & $\mathbf{8 0}$ & $\mathbf{1 0}$ & $\mathbf{4 0}$ & $\mathbf{8 0}$ \\
\hline \hline $\boldsymbol{R}(\Omega)$ & 11.18 & 12.00 & 14.30 & 13.35 & 14.09 & 16.92 \\
\hline $\boldsymbol{L}(\mu \mathrm{H})$ & 213.7 & 212.6 & 204.2 & 231.4 & 226.1 & 221.9 \\
\hline $\boldsymbol{f}_{s, \boldsymbol{c}}(\mathbf{k H z})$ & 53.15 & 54.91 & 62.82 & 51.29 & 53.86 & 62.43 \\
\hline $\boldsymbol{I}_{\boldsymbol{p k}, c}(\mathbf{A})$ & 10.28 & 7.96 & 3.60 & 8.64 & 6.75 & 2.77 \\
\hline$\theta_{1, c}\left({ }^{\circ}\right)$ & 17.24 & 34.31 & 60.58 & 17.35 & 35.17 & 62.66 \\
\hline $\boldsymbol{T}_{C F, c}(\mu \mathbf{s})$ & 0.60 & 0.70 & 1.02 & 0.63 & 0.75 & 1.20 \\
\hline
\end{tabular}

$\left(1^{\prime}\right) \sim\left(6^{\prime}\right)$, the calculated waveforms under critical ZVS condition can be obtained as shown in Fig. 15(a), (b), (c), using MATLAB program; and consequently, the four critical parameters $\boldsymbol{f}_{s, c}, \boldsymbol{I}_{p k, c}, \boldsymbol{\theta}_{1, c}, \boldsymbol{T}_{C F, C}$ can be determined and the results are obtained as shown in Table 1 (lower part) and plotted as curves in Figs. 16 19.

\section{Conclusion}

The circuit operation of phase-shift inverter under ZVS and NON-ZVS operating conditions for induction heating has been already presented both theoretically and experimentally. There are three main important points to be concluded here as follows:

1. There are two possibilities for the phase-shift controlled inverter circuit to operate under ZVS or NON-ZVS conditions which can be determined by the four critical circuit parameters; that is, for the inverter circuit to be operated under ZVS condition, load peak current $\boldsymbol{I}_{p k}$, switching frequency $\boldsymbol{f}_{s}$ and fundamental output voltage-current phase-lag $\boldsymbol{\theta}_{1}$ must be greater than their critical values, while the fully charging time of the inverter branch capacitor must be smaller than its critical value.

2. For output power reduction, increase of phase-shift without slight increase of switching frequency results in the switching frequency $\boldsymbol{f}_{s}$ and fundamental output voltagecurrent phase-lag $\boldsymbol{\theta}_{1}$ to be less than their critical values $\boldsymbol{f}_{s, c}$ and $\boldsymbol{\theta}_{1, c}$ respectively; which results in NON-ZVS operating condition. This is due to the recharge of capacitor reversecurrent which follows immediately after its unsuccessful discharge.

3 . For a great reduction of output power with large increase of phase-shift, the load current in this case becomes insufficient for an entire discharge of the inverter branch capacitor. Thus, the critical values of these parameters and consequently ZVS operating condition can not be obtained.

(Manuscript received May 9, 2005, revised Nov. 28, 2005)

\section{References}

( 1 ) P. Viriya and T. Thomas: "Power Transfer Characteristics of a Phase-shift Controlled ZVS Inverter for the Application of Induction Heating", Proc. Int. Power Electron. Conf., Tokyo, Japan, pp.423-428 (2000)

( 2 ) L. Grajales, J.A. Sabate, K.R. Wang, W.A. Tabisz, and F.C. Lee: "Design of a $10 \mathrm{~kW}, 500 \mathrm{kHz}$ Phase-Shift Controlled Series-Resonant Inverter for Induction Heating", Proc. of Ind. Appl. Soc., pp.843-849, Toronto, Canada (1993)

( 3 ) J.A. Sabate, R.W. Farrington, M.M. Jovanovic, and F.C. Lee: "Effect of Switch Capacitance on Zero-Voltage Switching of Resonant Converters", Proc. Appl. Power Electron. Conf., pp.213-220 (1992)

Pichetjamroen Viriya (Non-member) received the B.Eng. (Hons) de-

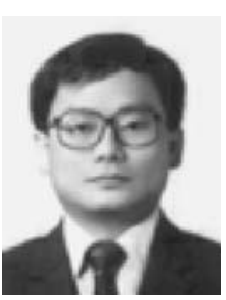
gree in electrical engineering from King Mongkut's Institute of Technology Ladkrabang (KMITL), Thailand, in 1975 and received the M.Eng. and D.Eng. degrees from Tokai University and Meiji University, Japan, in 1978 and 1990, respectively. He joined the faculty of KMITL as a lecturer of electrical engineering since 1978, at present holding the position of Associate Professor. His research interests are in analysis of power electronics circuits and control, highfrequency converter and high-frequency induction heating, melting, cooking and welding etc.

Naras Yongyuth (Non-member) received the B.Eng. and M.Eng. de-

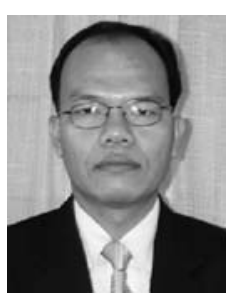
grees in electrical engineering from King Mongkut's Institute of Technology Ladkrabang (KMITL), Thailand, in 1992 and 2002, respectively. He joined the faculty of Siam University in Bangkok as a fulltime lecturer of electrical engineering since 1993. $\mathrm{He}$ is currently working toward the D.Eng. degree at KMITL. His research interests are power electronic circuits, high-frequency resonant converters, soft-switching converters.

Ichiro Miki (Member) received the B.S., M.S., and Ph.D. degrees in

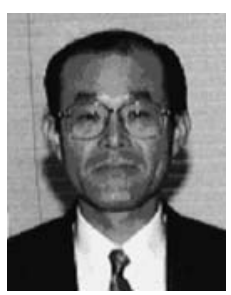
electrical engineering from Meiji university, Tokyo, Japan, in 1973, 1975, and 1981, respectively. Since 1978, he has been with the Department of Electrical and Electronic Engineering, Meiji University, Kawasaki, Japan, where he is currently a full Professor. His research interests include electric machines and ac motor control.

Kouki Matsuse

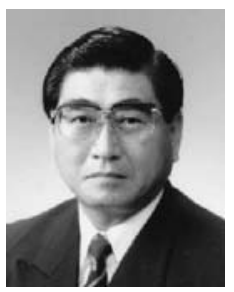

Member) received the B.E., M.E., and Ph.D. degrees in electrical engineering from Meiji university, Tokyo, Japan, in 1966, 1968, and 1971, respectively. Since 1979, he has been a full Professor in the Department of Electrical Engineering, Meiji University and, since 1996, he has served as the Dean of the School of Science and Technology. He has authored 60 published IEEE Transactions-class papers, 113 published refereed full-conference papers, and is the holder of 14 patents including 4 U.S. patents. He is the coauthor of 7 books and coeditor of "Sensorless Control of AC Motor Drives"(Piscataway, NJ: IEEE Press, 1996). His research interests are power electronics, microprocessor-based controllers for static power converters and drives, sensorless control of ac motor drives, and ac machines. He serves as the Chairperson of the Japanese National Committee of IEC/TC22 (Power Electronic Systems and Equipment). Dr. Matsuse was a Member-at-Large of the IEEE Industry Applications Society (IAS) Ecacutive Board for 1998 to 2001. He received the IEEJ Outstanding Paper Award in 1992, the IEEE IAS Electric Machines Committee Paper Award in 1997, the IEEE IAS Outstanding Achievement Award in 2000, and the IEEJ Outstanding Achievement Award in 2003 